\title{
Fatigue Cyclic Tests on Artificially Cemented Soil
}

REFERENCE: Viana da Fonseca, A., Rios, S., Amaral, M. F., and Panico, F., "Fatigue Cyclic Tests on Artificially Cemented Soil," Geotechnical Testing Journal, Vol. 36, No. 2, 2013, pp. 1-9, doi:10.1520/GTJ20120113. ISSN 0149-6115.

\begin{abstract}
Artificially cemented soils are frequently used in the infrastructural layers of road or railway platforms but the durability of these structures is often questioned when subjected to cyclic loads. In order to evaluate the fatigue behavior, this paper presents long cyclic triaxial tests over several soil cement mixtures using a very well graded silty sand and Portland cement. In undrained cemented tests, pore pressure decreased as a sign of plastic degradation, resulting that the effective stresses rose during the tests. For that reason, the resilient moduli were normalized to the effective stress, revealing a clear drop on the normalized resilient modulus at a number of cycles depending on the porosity/cement ratio. Notwithstanding, drained and undrained tests presented in this paper performed in uncemented and cemented specimens showed a distinct behavior from granular materials (where the shakedown theory applies) revealing a continuous increase in the accumulated permanent deformations, indicating that long term cyclic triaxial tests, with large number of cycles, may be decisive for a reliable characterization of cyclic triaxial test for bound mixtures.
\end{abstract}

KEYWORDS: cemented soils, pore pressure, porosity/cement ratio

\section{Introduction}

Subgrade soils are an important component of highway-pavement and railway-track support systems. The degradation of subgrades is frequently the major problem in these structures, giving rise to high maintenance costs and reduced serviceability. The main causes of deterioration are the accumulation of plastic deformation and the resilient cyclic deformation leading to pavement cracking by fatigue (Lekarp et al. 2000a,b). The increase in strength and stiffness of these cement treated materials is very important and therefore, reasonable soils can be converted in good materials for works with strict requirements in terms of mechanical properties (Mitchell 2008). This is especially attractive when high traffic loads, with considerable number of passages/cycles, demand for high mechanical properties of subgrades. This technique also brings economic and environmental advantages avoiding the exploitation of quarries and borrows areas, as well as reducing transportation of materials.

For that reason, artificially cemented soils are frequently used in the infrastructural layers of road or railway platforms as soilcement sub-bases, or stabilized subgrades by improving the soil with small amounts of Portland cement. However, the durability of soil-cement layers is often questioned when subjected to cyclic loads, such as the frequent passage of trains and vehicles.

Several authors have been studying the cyclic behavior of unbound soils (e.g. Li and Selig 1996; Puppala et al. 2009), granular materials (e.g. Lekarp 2000a,b; Werkmeister 2003) and, soft rocks (Yoshinaka and Osada 1995; Peckley and Uchimura 2009); however few studies have been published on cemented soils subjected to

Manuscript received June 13, 2012; accepted for publication November 28, 2012; published online January 24, 2013.

${ }^{1}$ Dept. of Civil Engineering, Faculty of Engineering of the Univ. of Porto (FEUP), R. Dr. Roberto Frias, s/n, 4200-465 Porto, Portugal (e-mail: sara.rios@fe.up.pt). long term cyclic conditions, especially soil-cement mixtures for subgrading or transition technical blocks in transport infrastructures.

In granular materials the degradation process due to cyclic loading is well defined by the "Shakedown" concept. According to Yu et al. (2007), the basic assumption of this theory is that below a certain load (named shakedown load) the structure will eventually shakedown, i.e., the ultimate response will be purely elastic (reversible) and; therefore, there is no more accumulation of plastic strain. If the applied load is higher than the shakedown load, uncontrolled permanent deformations will develop (designated in extreme as a "failure" or "ultimate" mode), and therefore unstable conditions will arise in platforms or other structures in transport systems. The term "structure" is used by Yu et al. (2007) in a general sense, since it was first applied to conventional engineering structures, but it can also be applied to multi-layer systems of unbound granular materials (UGM) subjected to repeated loads. This concept is very important as designers and contractors may focus their limit state concepts to critical stress level between stable and unstable conditions. Therefore, the European Standard Committee has included in the actual standard for UGMs under cyclic loads (CEN 2004) three classification ranges according to the work of Werkmeister et al. (2005), as illustrated in Fig. 1:

Range A-plastic shakedown-stable deformation behavior;

Range B-plastic creep-failure at a high number of load cycles;

Range $\mathrm{C}$-incremental collapse-failure at low number of load cycles.

The results presented in this paper show that this theory may not be adequate to reproduce the behavior of bound mixtures, specifically by analyzing the results obtained in an extensive experimental program testing a silty sand in uncemented and cemented conditions.

\section{Equipment}

The equipment used in this experimental program is the cyclic triaxial apparatus illustrated in Fig. 2, which includes a conventional triaxial cell equipped with an internal load cell and two or three 


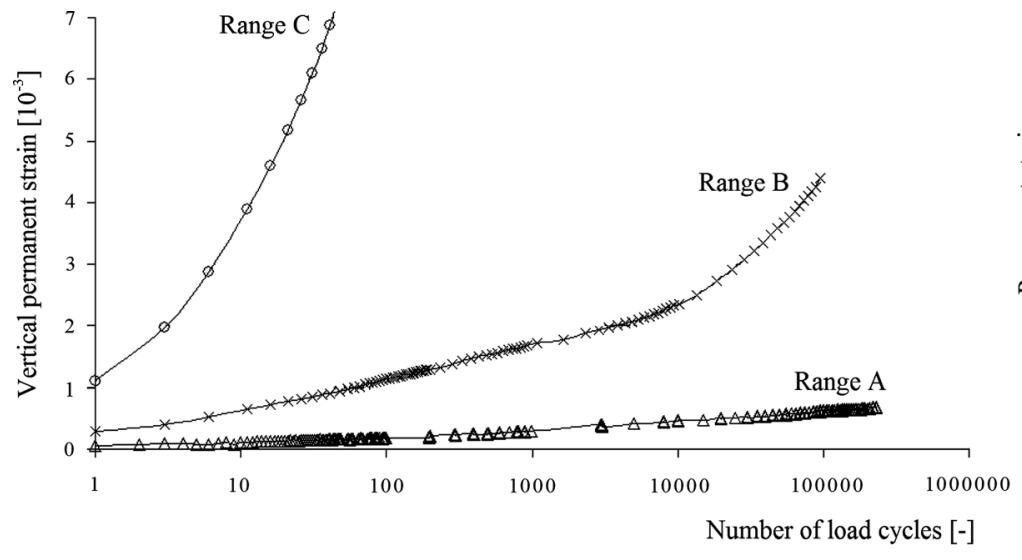

(a)

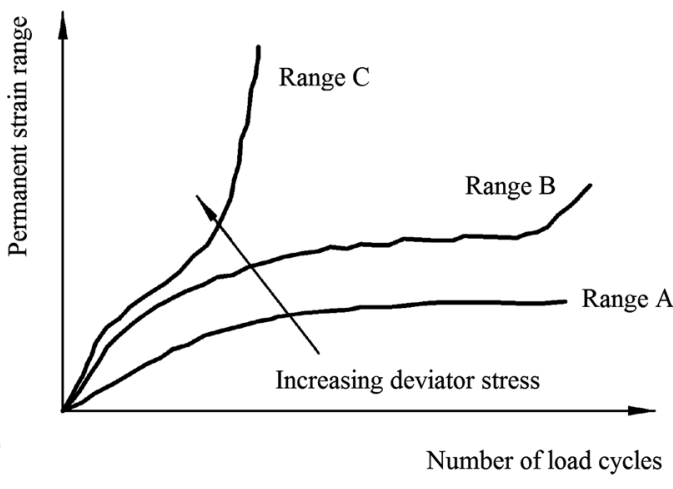

(b)

FIG. 1-Evolution of the accumulated permanent deformation with the number of cycles in the three classification ranges: (a) Werkmeister et al. (2005), (b) CEN (2004).

(depending on the specimen) linear variable displacement transducers (LVDT) for internal axial displacement measurements. Cell and back pressures were actuated by high performance pressure/volume regulators, controlled during saturation by specific LabView software precisely developed for that purpose. The system comprised a hydraulic unit and servo-actuator, as well as a motor and hydraulic pump, controlled by Dyna Tester software, developed in the Faculty of Engineering, Univ. of Porto, specifically designed for control and data acquisition during cyclic triaxial tests.

\section{Specimen Preparation and Materials}

The soil tested in this study was a silty sand originated by weathering of Porto granite, a rock quite abundant in the north and cen- tral region of Portugal (Viana da Fonseca et al. 2006). Consequently, this soil is often used in road and railway embankments since it is a very well graded soil with $30 \%$ of non-plastic fines. It is classified as a silty sand (ASTM D2487-98) in the Unified Classification System. Solid particles' density is 2.72, and the grain size distribution curve presents an effective diameter, $\mathrm{D}_{50}$, of $0.25 \mathrm{~mm}$, and uniformity and curvature coefficients of 113 and 2.7, respectively (Consoli et al. 2011). Tap water and high initial strength Portland cement (CEM I 52.5 R; specific gravity of 3.1) were mixed with it. The particle size distribution of the different mixtures was kept constant throughout the study. Since the cement contributed to more fines in the mixture, and this fines' content (FC) could influence the consistency of the indicial analyses, an equal quantity of soil fines to the amount of added cement

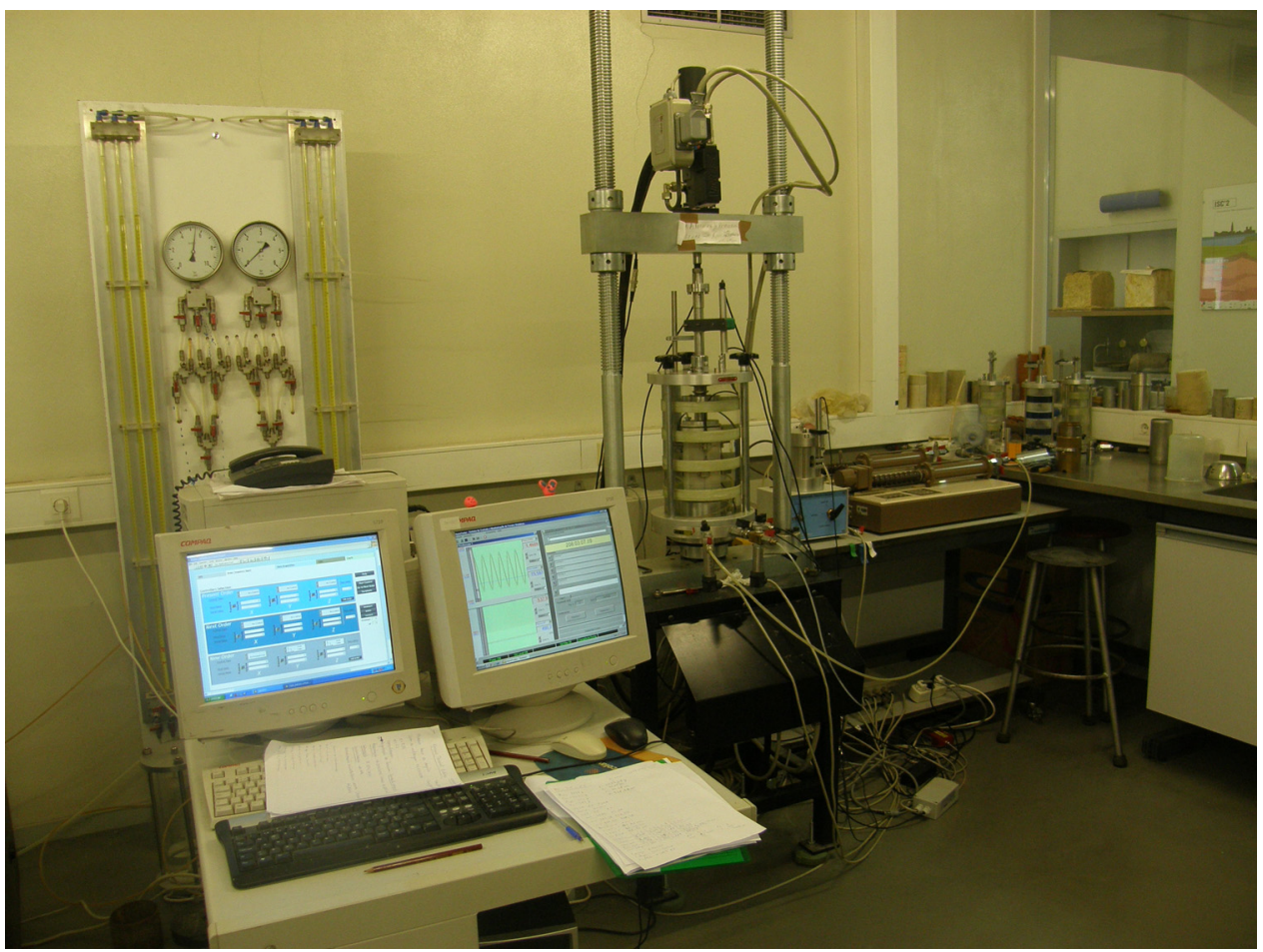

FIG. 2-Cyclic triaxial apparatus used in the experimental program. 
(in weight) was subtracted from the soil, minimizing the dependence of that state to FC.

The specific gravity of the cement-soil mixture was computed as a weighted average of the density of the soil $\left(G_{S}=2.72\right)$ and that of the cement $\left(G_{s}=3.1\right)$, being therefore adjusted for different cement contents.

After weighing the soil, cement and water, the soil and cement were mixed until reaching uniform consistency. Water was then added while continuing mixing until a homogeneous paste was created, the quantity of water being based on the target moisture content. The amount of cement for each mixture was determined from the mass of the dry soil in order to achieve the desired cement content. The soil-cement mixture was then stored in a covered container to avoid moisture loss until it was subjected to static compaction. The compaction was carried out in three layers in a cylindrical stainless steel mold that had been lubricated, being the specimen top and bottom compressed equally. Each layer was slightly scarified for better interlocking with the following layer. After extracting the specimen from the mold, the weight and dimensions were measured with accuracies of $0.01 \mathrm{~g}$ and $0.02 \mathrm{~mm}$, respectively. The uncemented specimen was immediately tested in the triaxial cell, while the cemented specimens were cured in a humid chamber for 26 days, at $23^{\circ} \mathrm{C} \pm 2^{\circ} \mathrm{C}$ temperature and $95 \%$ relative humidity, following 2 days submerged in water to improve saturation. A similar compaction procedure was used by Amaral et al. (2011) and Rios et al. (2012).

\section{Test Conditions}

After curing, the specimens were then placed in the triaxial cell and the water was allowed to percolate until a volume of water higher than twice the volume of voids is obtained. The saturation stage followed, increasing both cell and back pressure at the same constant rate of $20 \mathrm{kPa} / \mathrm{h}$, keeping a constant isotropic mean effective stress $\left(\mathrm{p}^{\prime}\right)$ of $10 \mathrm{kPa}$, until a back pressure value of $500 \mathrm{kPa}$ was achieved. This back-pressure value was kept constant during $24 \mathrm{~h}$, assuring full-saturation which was verified at a preliminary stage of the tests by $\mathrm{P}$ wave velocity measurements (Yoshimi et al. 1989; Valle-Molina 2006; Viana and Coutinho 2008; Viana da Fonseca et al. 2009; Ferreira et al. 2011). Finally, the specimen was isotropically consolidated $\left(\sigma_{1}=\sigma_{2}=\sigma^{\prime}{ }_{\mathrm{c}}\right)$ to the desired $\mathrm{p}^{\prime}$ increasing the cell pressure and waiting for the volume change to stabilize completely.

The cyclic loading was performed as indicated in Fig. 3, using a sinusoidal excitation of $1 \mathrm{~Hz}$, being the amplitude given by the difference between the maximum and minimum deviatoric stresses ( $q_{\max }$ and $q_{\mathrm{min}}$, respectively), defined as $q_{\mathrm{cyc}}=q_{\mathrm{max}}-q_{\mathrm{min}}$

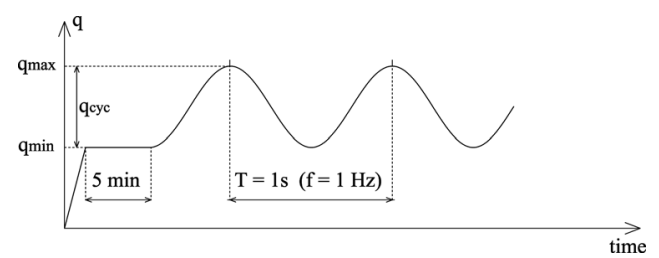

FIG. 3-Schematic representation of the cyclic load. where $q=\sigma_{v}-\sigma_{h}$. Frequency was chosen in order to allow the execution of tests with large number of cycles $\left(1 \times 10^{6}\right)$ in a reasonable time. The frequency of $1 \mathrm{~Hz}$ is also consistent with the practical purposes of the present paper, which is aimed at the study of the effect of cyclic loading in subgrades for high-speed roads. The frequency of $1 \mathrm{~Hz}$ results from the compromise between full-drainage in the specimens (by applying very low frequencies) and high number of cycles in a reasonable testing time.

For these long tests the accumulated permanent (or plastic) deformation $\left(\varepsilon_{p}\right)$ and the resilient modulus $\left(E_{r}\right)$ were defined according to the European standard (CEN 2004). The accumulated permanent deformation at a certain cycle was defined as the axial deformation at the end of that cycle and the resilient modulus was measured in the unloading part of the cycle as illustrated in Fig. 4. In agreement to the standard suggestion, after the first 20 cycles, an average value of the resilient moduli obtained on the previous 10 cycles was calculated to obtain a representative value of that cycle, i.e., the resilient modulus at cycle 1000 corresponds to the average resilient modulus obtained from the cycles 990 to 1000 .

For simplicity, only certain cycles were analyzed, reducing the amount of data to be integrated in the interpretation, but still providing a very clear analysis of the evolution of the specimen behavior during the cycling test. The selected cycles were the following:

[ 1 to $20 ; 50 ; 100 ; 200 ; 400 ; 1000 ; 2500 ; 5000 ; 7500 ; 10000$; $12500 ; 15000 ; 20000 ; 30000 ; 50000 ; 70000 ; 100000$; $150000 ; 200000 ; 300000 ; 400000 ; 500000 ; 700000$; $1000000]$.

The decision between opening or closing the drainage valve is not simple since both conditions present advantages and disadvantages. When the drainage valve is opened, it is difficult to have accurate volume changes measurements due to the rapid loading and the compliance caused mainly by the small diameter of the drainage system (holes) as well as some flexibility of the tube lines. On the contrary, in undrained tests the effective stress is not constant due to the generation of negative or positive excess pore pressures and thus, the influence of effective stresses is not possible to evaluate, unless a normalization is applied as will be discussed below. For that reason, the results presented herein show the results obtained in both conditions Due to the physical properties of the soil (hydraulic conductivity and fines content) and the frequency of loading, when the drainage valve is opened, the test is only partially drained. In any case, since the level of

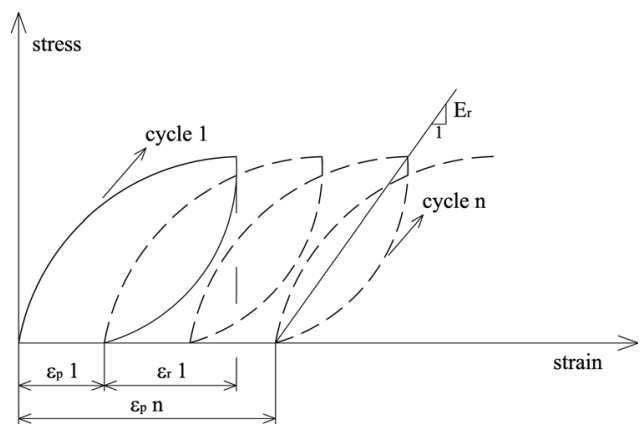

FIG. 4-Definition of permanent deformation and resilient modulus. 
TABLE 1-Molding and test conditions of the tests performed at lower stress levels.

\begin{tabular}{|c|c|c|c|c|c|c|c|c|c|}
\hline Test Name & Cement Content, $\%$ & Moulding Water Content, \% & Initial Void Ratio, $\mathrm{e}_{0}$ & $n / C_{i v}^{0.21}$ & $q_{\mathrm{min}}, \mathrm{kPa}$ & $q_{\max }, \mathrm{kPa}$ & $\sigma_{c}^{\prime}, \mathrm{kPa}$ & No. Cycles & Draining Conditions \\
\hline LS_0\%_D & 0 & 12 & 0.79 & N/A & 5 & 45 & 30 & 500000 & Drained \\
\hline LS_2\%_U & 2 & 12 & 0.76 & 43 & 5 & 45 & 30 & 500000 & Undrained \\
\hline
\end{tabular}

Note: $n / C_{i v}^{0.21}$-ratio of porosity to the volumetric cement content.

plastification and the volumetric strains are very low, it is reasonable to assume that the drainage is substantial, which is confirmed by the different behavior between the two conditions shown ahead.

\section{Tests at Lower Stress Levels}

This experimental program started with tests performed over three different specimens (one uncemented and the other two cemented with distinct cement contents) subjected to loads representative of the stress conditions existing in the bases and sub-bases of transportation infrastructures platforms. In that sense, a maximum amplitude of $40 \mathrm{kPa}$ was applied together with $30 \mathrm{kPa}$ of effective confining pressure $\left(\sigma_{\mathrm{c}}^{\prime}\right)$ as indicated in Table 1 . The cemented specimens were tested undrained while the uncemented specimen was tested partially drained because in undrained conditions it suffered liquefaction in less than 100 cycles, due to the rapid increase of pore pressure.

For the distinct tests, the following labels were adapted: LS for low stress level; X \% for the cement content (e.g., $2 \%$ ); and D for drained and $\mathrm{U}$ for undrained testing conditions.

Molding conditions of the cemented specimens were also defined by the adjusted porosity/cement ratio which is the ratio of porosity to the volumetric cement content (expressed as the ratio of the volume of cement to the total volume) adjusted by an exponent $\left(n / C_{i v}^{x}\right)$. In fact, mixing soil with Portland cement has been considered an attractive solution and a rational approach based on specific index to define the molding conditions, was proposed by Consoli et al. (2007), showing that for unsaturated mixtures, such as the ones used in the earthworks, this ratio is very convenient for mechanical properties evaluation. Working with this index for this particular soil, Rios et al. (2012) found that it could be adjusted with an exponent of 0.21 in the volumetric cement content $\left(n / C_{i v}^{0.21}\right)$ revealing high values of determination coefficients $\left(R^{2}\right)$ for strength and stiffness properties.

Figure 5 presents the evolution (in terms of the number of cycles) of the accumulated permanent deformation obtained for each test of Table 1.

The uncemented specimen (LS_0\%_D) showed a continuous increase in the accumulated permanent deformation without any sign of stabilization conversely to what should be expected from a granular material following the shakedown theory expressed above. Using the three classification ranges presented in Fig. 1, Range B, corresponding to "Failure at high number of cycles", would be the most indicated. Although this soil cannot be assumed as a granular material due to the great amount of fines (around $30 \%$ ), other authors (e.g. Li and Selig 1996) have also found for fine grained soils a critical level of repeated deviator stress, above which soil plastic deformation increases with cyclic loading. Therefore, it seems that the applied low stress levels are still higher than the "so-called" shakedown load for this cemented material.

The $2 \%$ cement content specimen (LS_2\%_U) also showed an increase in the accumulated permanent deformation which tends to be even more accentuated after 20000 cycles, possibly corresponding to the onset of bonding degradation, that is to breaking of cemented structure. It is interesting to notice that the rate of the permanent deformation accumulation in the first 20000 cycles is higher in LS_0\%_D than in LS_2\%_U. This means that the cemented bonds were preventing the development of plastic strains, but once they were destroyed, the rate of increase of plastic strains rises rapidly (exponentially). For this reason, after half million cycles the final accumulated deformation is almost the same for the two tests.

The $7 \%$ cement content specimen (LS_7\%_U) showed no plastic strains, which might be explained by the specimen's stiffness compared to the low loading level tests, resulting in very small strains development, possibly smaller than the instrumentation sensitivity. For this reason, tests with higher loads were performed which are analyzed in the next section.

In Fig. 6 the resilient modulus $\left(E_{r}\right)$ results are shown for the three tests. The high scatter observed in LS_7\%_U is due to the very low strain values developed in this test. However, it is still possible to observe that the resilient moduli obtained in this test were higher than the moduli obtained in the other tests with lower cement content, indicating that cement has a significant effect in the stiffness increase. In terms of the evolution with the number of cycles, a slight increase in $E_{r}$ is observed in the cemented specimens after 10000 cycles, despite the cement degradation indicated

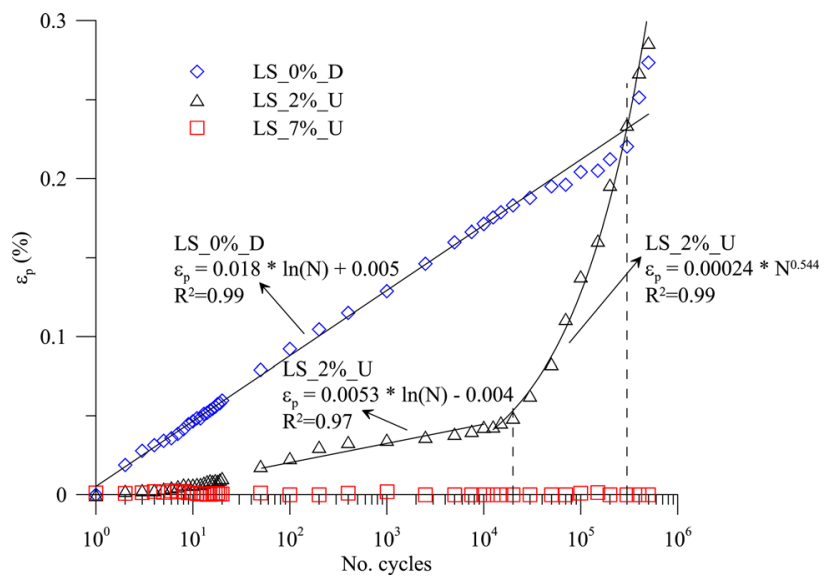

FIG. 5-Evolution of the accumulated permanent deformation with the number of cycles. 


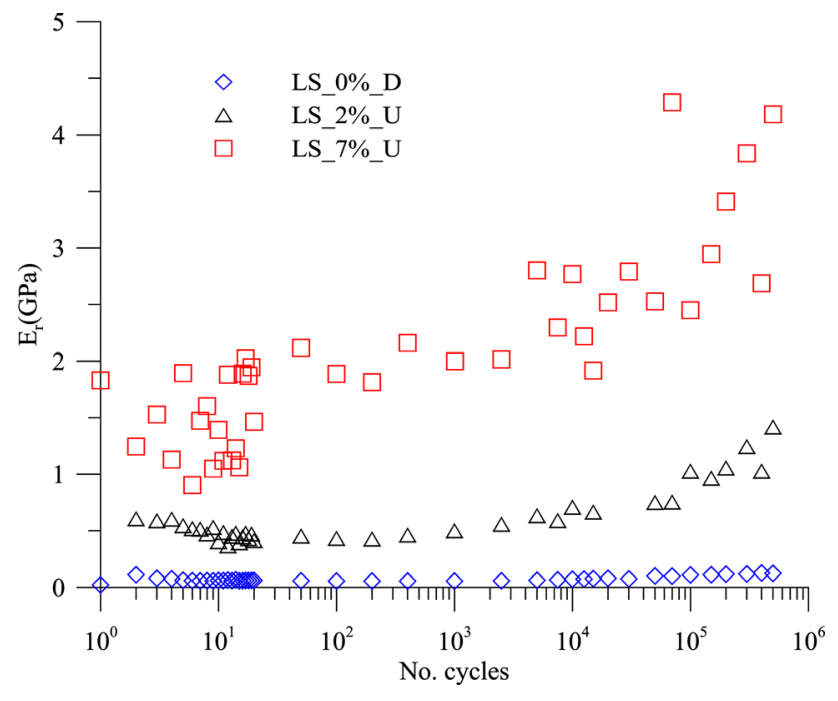

FIG. 6-Evolution of the resilient modulus with the number of cycles.

by the plastic strains. This means that the development of plastification does not seem to affect so much the stiffness as it does on the plastic (accumulated) deformations.

\section{Tests at Higher Stress Levels}

\section{Cyclic Loading}

Tests performed at higher cyclic stress levels were performed in order to fulfill the following aims: analyze specimens with higher cement contents, comparison of cemented specimens with different cement contents but the same porosity/cement ratio, and compare different drainage conditions. For that purpose, tests with $1 \times 10^{6}$ cycles were done in drained to partially drained conditions when the pore pressure valves were open and undrained conditions when close, over different specimens as indicated in Table 2. Fully drained conditions may not be achieved during the tests, however, the two conditions showed different results even for identical specimens, revealing the need to investigate the partially drained condition in the future with the assemblage of pore pressures probes directly applied to the face of the specimen, in the mid-height, to check for any significant difference in pore-pressures during cycling. The deviatoric loads were defined such as $q_{\min }$ and $q_{\max }$ corresponding, respectively, to $10 \%$ and $20 \%$ of the expected static peak strength $\left(q_{\text {peak }}\right)$, therefore with a $q_{\text {cyc }}$ of $10 \%$ of $q_{\text {peak }}$, being these reference values evaluated by Rios (2011) results. Such loading levels are expected to be in the elastic domain of the material (Rios 2011), assuring that the degradation of soil properties is only due to the fatigue phenomenon and not to soil yielding and admitting that dynamic aspects are not relevant for these frequencies. The test designation followed the same criteria defined before, that is, "HS" corresponds to tests at higher stress levels.

\section{Undrained Tests}

The first three tests of Table 2 were performed undrained which lead to the development of negative excess pore pressures and; consequently, to an increase of the effective stresses. Static triaxial tests performed on similar specimens and tested undrained, showed an increase in the excess pore pressure until an axial deformation of $1 \%$, reducing then the pore pressure to a stabilized value, generally below the initial pore pressure. This is in agreement with similar drained tests performed in static conditions, characterized by typical dilatant behavior associated to peak deviator stress and strain softening (Rios et al. 2011). In that sense, it is expected that a dilatant behavior is observed in the undrained cyclic triaxial tests if there is a development of increasing plastification due to cycling, with decreasing of pore pressure after a slight increasing at initial load cycles (a pseudo-elastic load range), as observed by Yeoh and Airey (1994) and Sharma (2004).

In Fig. 7 the increase of the mean effective stress with the number of cycles is shown for the three undrained tests of Table 2, as a result of the pore pressure reduction. Tests HS_3\%_U and HS_5\%_U start with the same stress level because the same peak deviator was observed in static conditions from which the values of $20 \%$ and $10 \%$ of the peak deviator stress were calculated.

Figures 8,9 , and 10 show the effective $\left(q\right.$ versus $\left.p^{\prime}\right)$ and total ( $q$ versus $p$ ) stress paths obtained in each test. Once again, only selected cycles were studied, providing a simplified analysis of the stress-paths evolution, being clear the different mean effective stress paths along cycling.

These graphs show that increasing cement content results in a reduced change in the effective stresses meaning that the cement prevents the increase of the effective stresses as a result of pore pressure reduction. The decrease in the pore pressure only occurs when the cemented bonds start to break, and thus it is a sign of plastic degradation. In that sense, it is expected that in the $3 \%$ cement content specimen, the pore pressure decreases more

TABLE 2-Molding and test conditions of the tests performed at lower stress levels.

\begin{tabular}{|c|c|c|c|c|c|c|c|c|c|c|}
\hline $\begin{array}{l}\text { Test } \\
\text { Name }\end{array}$ & $\begin{array}{c}\text { Cement } \\
\text { Content, \% }\end{array}$ & $\begin{array}{c}\text { Moulding Water } \\
\text { Content, } \%\end{array}$ & $\begin{array}{l}\text { Initial Void } \\
\text { Ratio, } \mathrm{e}_{0}\end{array}$ & $n / C_{i v}^{0.21}$ & $q_{\min }, \mathrm{kPa}$ & $q_{\max }, \mathrm{kPa}$ & $q_{\text {peak }}, \mathrm{kPa}$ & $\sigma_{c}^{\prime}, \mathrm{kPa}$ & $\begin{array}{c}\text { No. } \\
\text { Cycles }\end{array}$ & $\begin{array}{l}\text { Draining } \\
\text { Conditions }\end{array}$ \\
\hline HS_3\%U & 3 & 12 & 0.65 & 36 & 100 & 200 & 1000 & 40 & 1000000 & Undrained \\
\hline HS_5\%U & 5 & 12 & 0.74 & 36 & 100 & 200 & 1000 & 40 & 1000000 & Undrained \\
\hline HS_7\%U & 7 & 12 & 0.62 & 29 & 250 & 500 & 2500 & 40 & 1000000 & Undrained \\
\hline HS_3\%D & 3 & 12 & 0.73 & 39 & 84 & 168 & 840 & 40 & 1000000 & Drained \\
\hline HS_5\%D & 5 & 12 & 0.75 & 36 & 145 & 290 & 1450 & 40 & 1000000 & Drained \\
\hline HS_7\%D & 7 & 12 & 0.75 & 33 & 195 & 390 & 1950 & 40 & 1000000 & Drained \\
\hline
\end{tabular}

Note: $q_{\text {peak }}-$ expected static peak strength; $n / C_{i v}^{0.21}$-ratio of porosity to the volumetric cement content. 


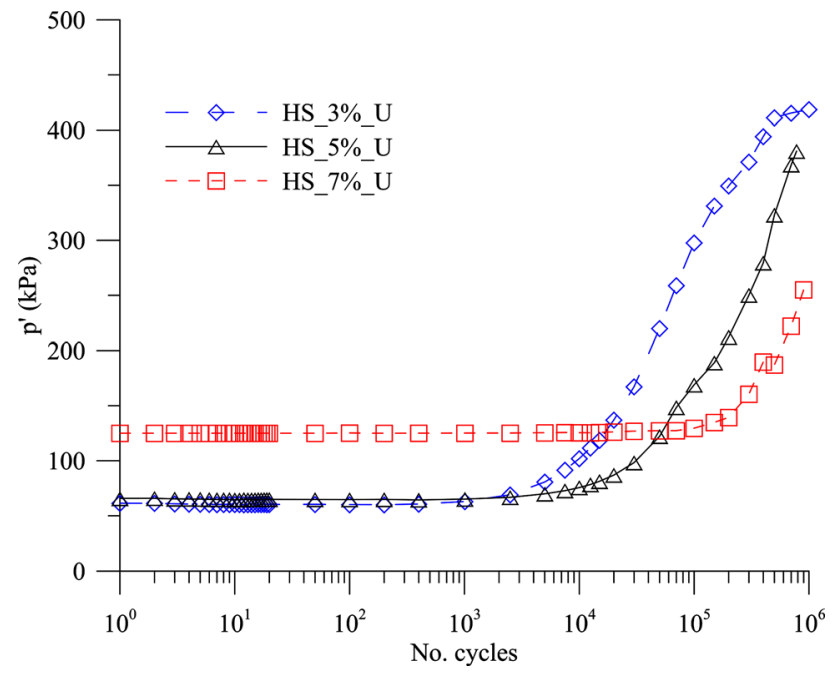

FIG. 7-Evolution of the mean effective stress with the number of cycles for the three undrained tests at higher stress levels.

rapidly than in the other specimens, which is observed indirectly in Fig. 7 by the evolution of the mean effective stress of each cycle. In the HS_3\%_U test the mean effective stress starts to increase at a lower number of cycles than in the others. Moreover, while in the HS_3\%_U the mean effective stress tends clearly to stabilize around 500000 cycles, in the HS_5\%_U, this is not so distinct since the test ended a bit earlier than the other, while in HS_7\%_U it seems that the effective stress is increasing continuously. It results that the number of cycles needed to fully understand the soil-cement behavior depends on the molding conditions and degree of cementation. Another interesting issue is that the cement content seems to have a determinant influence on the behavior, irrespectively of the porosity cement ratio $\left(n / C_{i v}{ }^{0.21}\right)$, since HS_3\%_U and HS_5\%_U were done with different cement contents but the same ratio, presenting distinct behaviors. The transient behavior that is still in development during cycling, may be the reason for such different behavior as the plastification of such structured matrices depend differently on time.

This does not seem to happen in the resilient modulus presented in Fig. 11 where $n / C_{i v}{ }^{0.21}$ has a higher influence. Since the effective stress was not constant during the test due to the pore

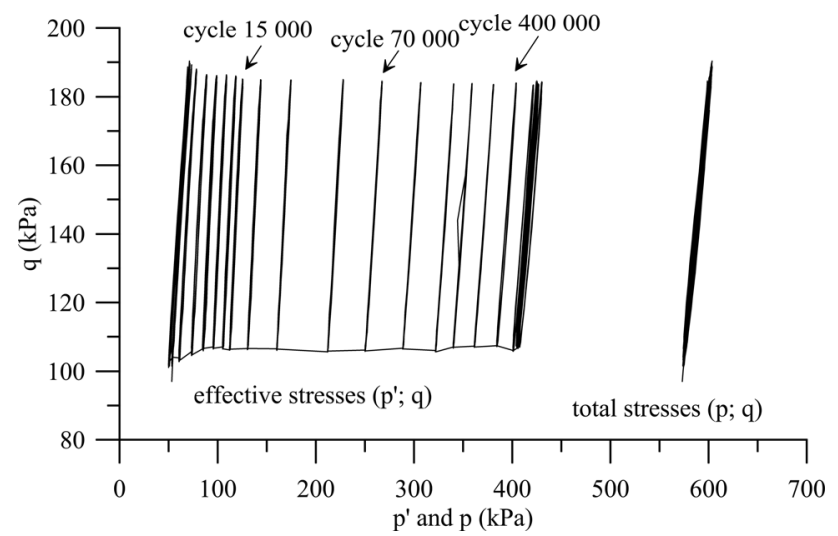

FIG. 8-Effective and total stress-paths for the HS_3\%_U test.

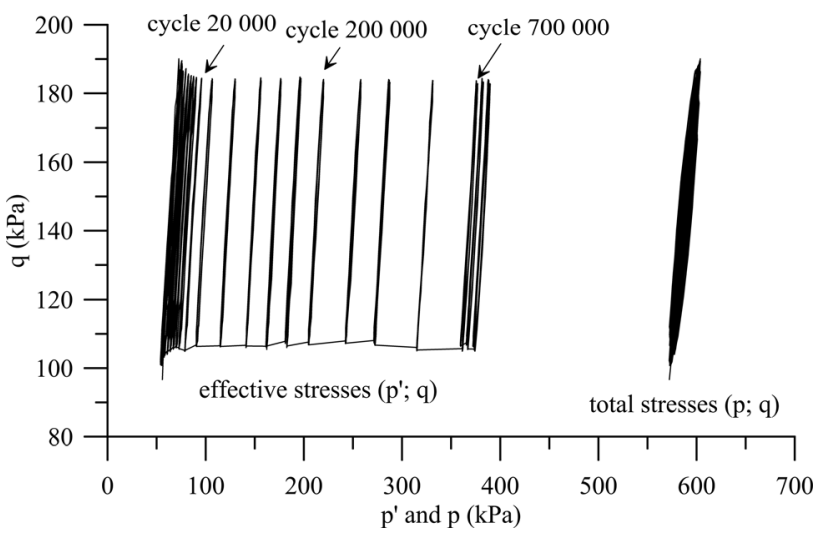

FIG. 9-Effective and total stress-paths for the HS_5\%_U test.

pressures reduction, the resilient modulus was normalized by the effective stress, in order to provide a much clear analysis of the stiffness evolution. The results show a clear drop on the normalized resilient modulus as a consequence of a much larger increase of the effective stress than the increase in the resilient modulus, which is a sign of cyclic yielding due to cement degradation. Although the absolute values are different, the number of cycles at which that drop occurs seems to depend on the porosity/cement ratio since in HS_3\%_U and HS_5\%_U (with $n / C_{i v}^{0.21}=36$ ) the drop occurs at 5000 cycles, while in HS_7\%_U (with $n / C_{i v}^{0.21}=29$ ) it occurs at 200000 cycles. Being necessary to explain with much more data, this is very interesting characteristic to be explored, since the porosity cement ratio can give an indication of the number of cycles at which the material will start to degrade.

The analysis of the accumulated permanent deformation, presented in Fig. 12, shows the same trend for each test. In the first 10000 cycles, where no relevant pore pressures reduction were observed in Fig. 7, the accumulated permanent deformation remains at low values, increasing significant after that.

\section{Partially Drained Tests}

In the partially drained tests the analysis of the resilient modulus revealed that it remained almost constant during the test, and thus,

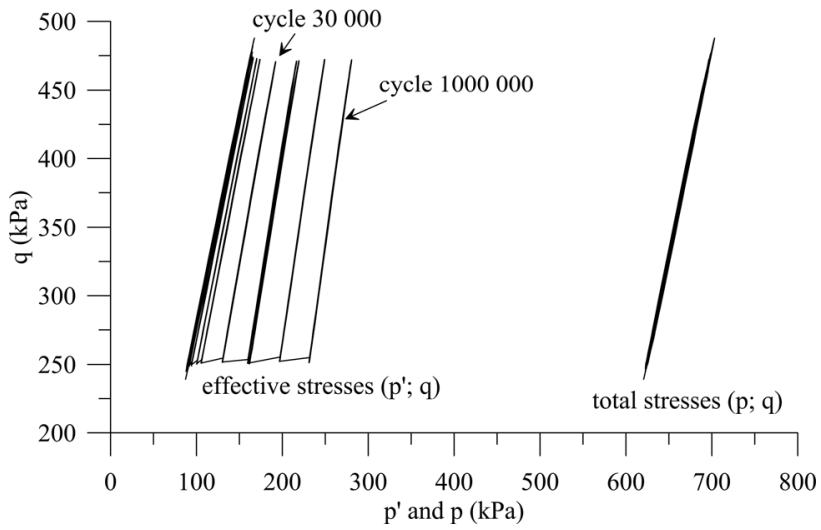

FIG. 10-Effective and total stress-paths for the HS_7\%_U test. 


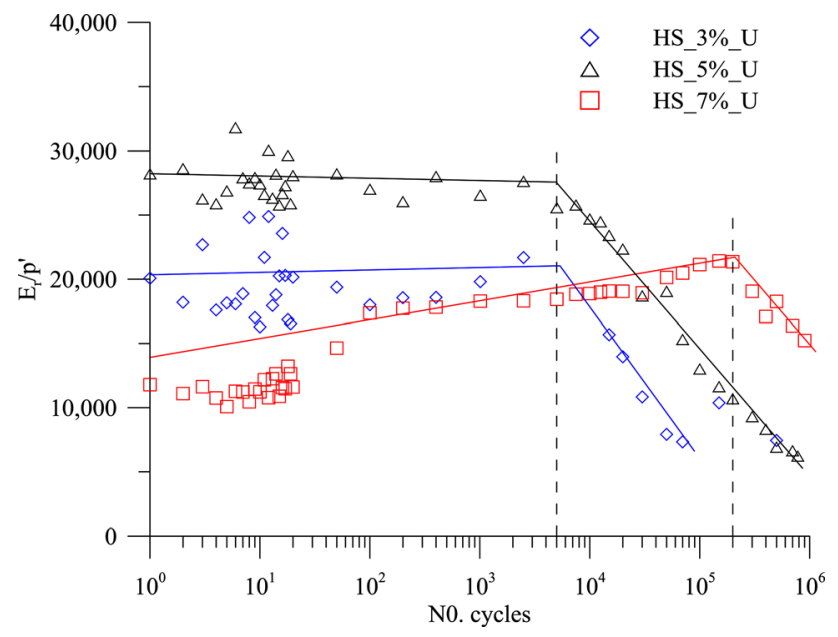

FIG. 11-Evolution of the normalized resilient modulus with the number of cycles for the three undrained tests at higher stress levels.

as the effective stress is also constant, the normalized modulus showed the trend of Fig. 13.

Comparing the $5 \%$ cement content specimens molded with $n / C_{i v}^{0.21}=36$ and tested in the two drainage conditions; the normalized resilient modulus is higher in drained conditions than in undrained conditions. This is additional evidence that the drained condition, even if not fully drained, exhibits a distinct behavior from the fully undrained condition. Rios (2011) has found a similar behavior in static conditions, reporting higher peak deviatoric strength in drained conditions than in undrained conditions.

In terms of accumulated permanent deformations, deviatoric and volumetric plastic deformations were distinguished, searching for different trends between them. As expressed by Figs. 14 and 15 , a similar trend was obtained in the evolution of both strains, where plastic strains remain very close to zero up to 10000 cycles increasing significantly after that. However, the volumetric strains are much higher than the deviatoric strains, indicating that permanent strains are essentially due to increase in volume which is in

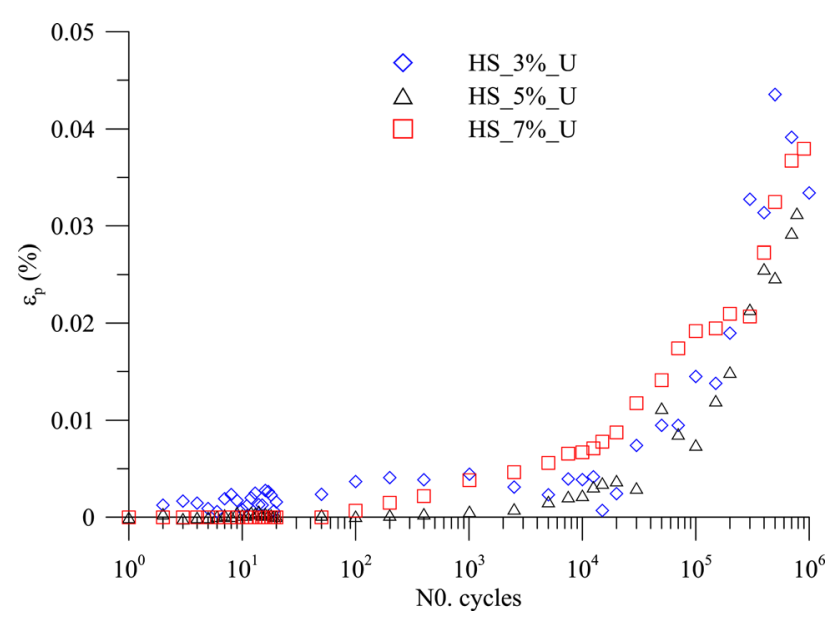

FIG. 12-Evolution of the permanent deformation with the number of cycles for the three undrained tests at higher stress levels.

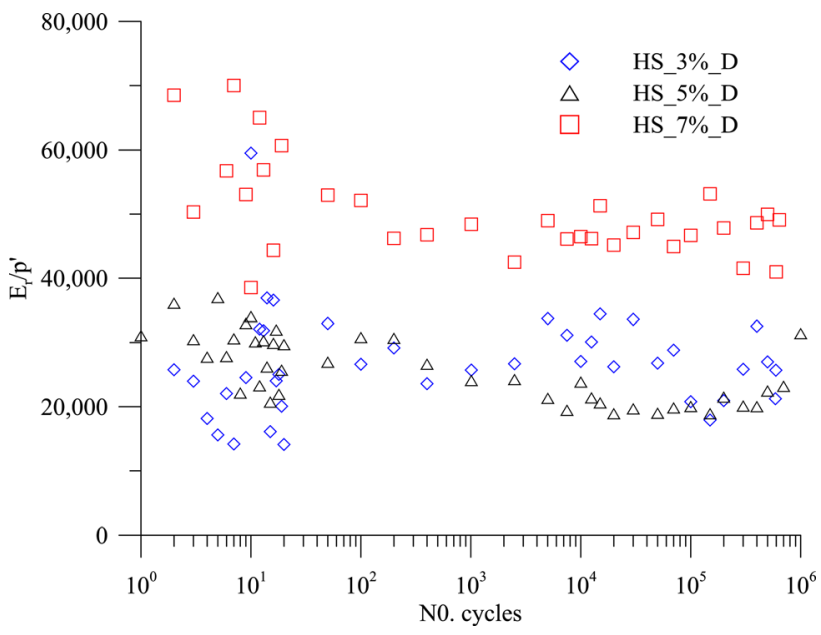

FIG. 13-Evolution of the normalized resilient modulus with the number of cycles for the three drained tests at higher stress levels.

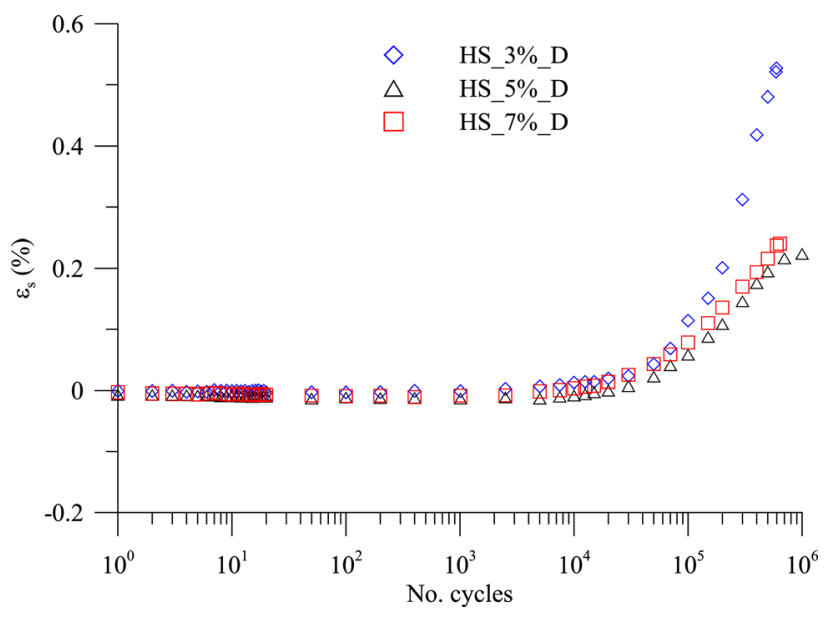

FIG. 14-Evolution of the deviatoric permanent deformation with the number of cycles for the three drained tests at higher stress levels.

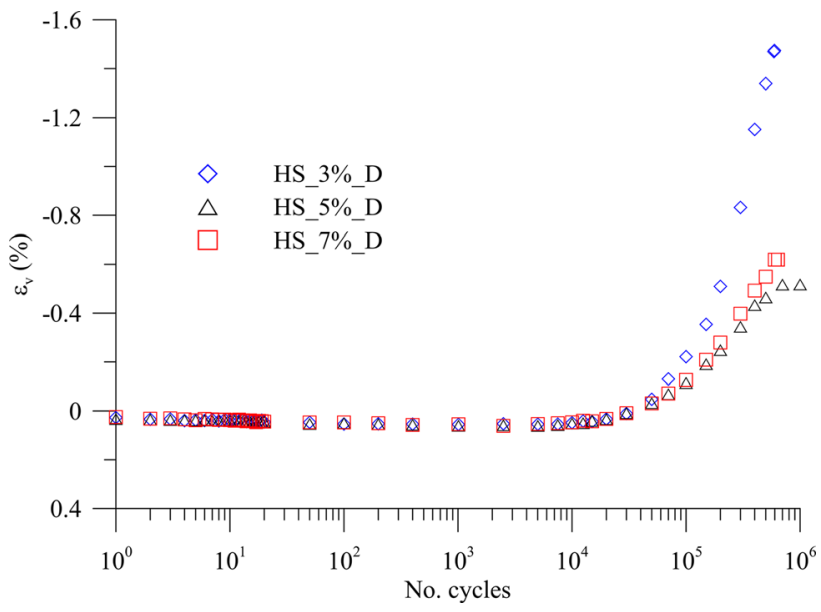

FIG. 15-Evolution of the volumetric permanent deformation with the number of cycles for the three drained tests at higher stress levels (Note that is this convention positive volumetric strains correspond to volume reduction). 
agreement with the dilatant behavior observed in cyclic undrained tests and in static tests.

Conversely to resilient results, higher accumulated deviatoric strains were observed in drained conditions than in undrained. This may be explained by the higher effective confining stresses of the undrained tests, due to the decrease in the pore pressures, preventing the development of higher strains.

\section{Conclusions}

Artificially cemented soils in cyclic conditions are not sufficiently studied in the literature. In this paper cyclic triaxial tests over several mixtures of a silty sand mixed with Portland cement were tested in drained and undrained conditions. This material showed a completely different performance from the typical behavior associated to granular materials which follow the shakedown theory.

Uncemented and cemented specimens with lower or higher stress levels always showed a continuous increase in the accumulated permanent deformation. In undrained tests, the increase in the permanent deformation is associated to a decrease in the pore pressure (and consequently on the increase in the effective stress) as a sign of dilation. For that reason, the resilient modulus was normalized by the mean effective stress, showing a clear drop, very much consistent to cyclic yielding due to cement degradation.

In drained or undrained conditions, the accumulated permanent deformation only achieves significant values after 10000 cycles, while the actual European standard for unbounded granular materials (CEN 2004) suggests tests up to 10000 cycles. These results indicate that artificially cemented soils should be better studied and standards have to adapt to their specificities, very different to unbound granular soils, so that patterns of behavior can be better understood. Therefore, long term cyclic triaxial tests, with large number of cycles (as high as up to $1 \times 10^{6}$ cycles), may be decisive for a reliable characterization of bound mixtures, especially for the application of these materials in subgrading in transportation infrastructures.

\section{Acknowledgments}

This research was developed under the activities of FCT (Portuguese Foundation for Science and Technology) research unit CEC, in FEUP through the projects PTDC/ECM/099475/2008, and [SIPAV: Innovative Precast Structural Solutions for HighSpeed Railway (SI IDT-3440/2008)], financed by the European Community (QREN/UE/FEDER), Operational Program for Competitive Factors “COMPETE”.

\section{References}

Amaral, M. F., Viana da Fonseca, A., Carvalho, J., and Consoli, N. C., 2011, "Dynamic Poisson Ratio Analysis," Proceedings of the 15th European Conference on Soil Mechanics and Geotechnical Engineering, Athens, Greece, Vol. 1, pp. 115-120.
CEN, 2004, "EN 13286-7-Unbound and Hydraulically Bound Mixtures-Part 7: Cyclic Load Triaxial Test for Unbound Mixtures," Comité Européen de Normalisation, Brussels.

Consoli, N., Viana da Fonseca, A., Cruz, R., and Rios, S., 2011, "Voids/Cement Ratio Controlling Tensile Strength of Cement Treated Soils," J. Geotech. Environ. Eng., Vol. 137, No. 11, pp. 1126-1131.

Consoli, N. C., Foppa, D., Festugato, L., and Heineck, K., 2007, "Key Parameters for Strength Control of Artificially Cemented Soils," J. Geotech. Geoenviron. Eng., Vol. 133, No. 2, pp. 197-205.

Ferreira, C., Viana da Fonseca, A., and Nash, D., 2011, "Shear Wave Velocities for Sample Quality Assessment on a Residual Soil," Soils Found., Vol. 51, No. 4, pp. 683-692.

Lekarp, F., Isacsson, U., and Dawson, A., 2000a, "State of the Art. I: Resilient Response of Unbound Aggregates," J. Transp. Eng., Vol. 126, No. 1, pp. 66-75.

Lekarp, F., Isacsson, U., and Dawson, A., 2000b, "State of the Art. II: Permanent Strain Response of Unbound Aggregates," J. Transp. Eng., Vol. 126, No. 1, pp. 76-83.

Li, D. and Selig, E. T., 1996, "Cumulative Plastic Deformation for Fine-Grained Subgrade Soils,” J. Geotech. Eng., Vol. 122, pp. 1006-1013.

Mitchell, J., 2008, "Mitigation of Liquefaction Potential of Silty Sands," GeoCongress 2008, pp. 433-451.

Peckley, D. and Uchimura, T., 2009, "Strength and Deformation of Soft Rocks Under Cyclic Loading Considering Loading Period Effects," Soils Found., Vol. 49, No. 1, pp. 51-62.

Puppala, A. J., Saride, S., and Chomtid, S., 2009, "Experimental and Modeling Studies of Permanent Strains of Subgrade Soils," J. Geotech. Geoenviron. Eng., Vol. 135, No. 10, pp. 1379-1389.

Rios, S., 2011, "A General Framework for the Geomechanical Characterisation of Artificially Cemented Soil," Ph.D. thesis, Univ. of Porto, Portugal.

Rios, S., Viana da Fonseca, A., and Baudet, B., 2012, “The Effect of the Porosity/Cement Ratio on the Compression Behaviour of Cemented Soil," J. Geotech. Geoenviron. Eng. Vol. 138, No. 11, pp. 1422-1426.

Sharma, S., 2004, "Characterisation of Cyclic Behaviour of Calcite Cemented Calcareous Soils," Ph.D. thesis, The Univ. of Western Australia, Perth.

Valle-Molina, C., 2006, "Measurements of Vp and Vs in Dry, Unsaturated and Saturated Sand Specimens With Piezoelectric Transducers," Ph.D. dissertation, Geotechnical Engineering, Dept. of Civil Engineering, The Univ. of Texas at Austin, Austin, TX.

Viana da Fonseca, A., Carvalho, J., Ferreira, C., Santos, J. A., Almeida, F., Pereira, E., Feliciano, J., Grade, J., and Oliveira, A., 2006, "Characterization of a Profile of Residual Soil From Granite Combining Geological, Geophysical and Mechanical Testing Techniques," Geotech. Geologic. Eng., Vol. 24, pp. 1307-1348.

Viana da Fonseca, A., Ferreira, C., and Fahey, M., 2009, “A Framework Interpreting Bender Element Tests, Combining Time-Domain and Frequency-Domain Methods," Geotech. Test. J., Vol. 32, No. 2, pp. 1-17.

Viana da Fonseca, A. and Coutinho, R. Q., 2008, "Characterization of Residual Soils," Geotechnical and Geophysical Site Characterisation, A-B. Huang and P. Mayne, Eds., Taylor \& Francis, London, pp. 195-248. 
Werkmeister, S., 2003, "Permanent Deformation Behaviour of Unbound Granular Materials in Pavement Constructions," Ph.D. thesis, Technischen Universität, Dresden, Germany.

Werkmeister, S., Dawson, A., and Wellner, F., 2005, "Permanent Deformation Behavior of Granular Materials and the Shakedown Concept," Int. J. Road Mater. Pavement Des., Vol. 6, No. 1, pp. 32-52.

Yeoh, C. K. and Airey, D. W., 1994, "Undrained Cyclic Loading of a Cemented Sand," Pre-failure Deformation of Geomaterials, Shibuya, Mitachi, and Miura, Eds., Balkema, Rotterdam, pp. 95-100.
Yoshimi, Y., Tokimatsu, K., and Hosaka, Y., 1989, "Evaluation of Liquefaction Resistance of Clean Sands Based on HighQuality Undisturbed Samples," Soils Found., Vol. 29, No. 1, pp. 93-104.

Yoshinaka, R. and Osada, M., 1995, "The Comparison Between Dynamic and Static Strength of Soft Sedimentary Rocks," Rock Foundation, Y. Kiruchi, Ed., Balkema, Rotterdam, pp. 109-114.

Yu, H. S., Khong, C., and Wang, J., 2007, “A Unified Plasticity Model for Cyclic Behaviour of Clay and Sand," Mech. Res, Commun., Vol. 34, pp. 97-114. 